\title{
The Impact of Climate Change on Ragweed Pollination
}

\author{
Robert K. Bush
}

Published online: 1 July 2011

(C) Springer Science+Business Media, LLC 2011

Trial: Ziska L, Knowlton K, Rogers C, et al.: Recent warming by latitude associated with increased length of ragweed pollen season in central North America. Proc Natl Acad Sci U S A 2011;108:4248-51.

Rating: $\bullet$ Of major importance.

Keywords Climate change $\cdot$ Ragweed $\cdot$ Pollination $\cdot$ Pollen Warming ' Latitude · Frost-free interval · Allergic rhinoconjunctivitis

Introduction: Although the cause of climatic warming trends is controversial, it is clear that the frost-free days increased at latitudes from $41.15^{\circ} \mathrm{N}$ (Papillion, NE) to $52.07^{\circ} \mathrm{N}$ (Saskatoon, Saskatchewan, Canada) during the period from 1995 to 2009. The authors hypothesize that the increase in the frost-free interval in the fall of the year could impact the duration of the ragweed pollen (an important aeroallergen) season in these areas.

Aims: The purpose of the study was to determine the effects of prolonged frost-free days on the duration of the ragweed pollen season.

Methods: Ragweed pollen counts (using volumetric samples) were analyzed from 10 National Allergy Bureau (United States) and Aerobiology Research Laboratories (Canada) at sites ranging from $30.63^{\circ} \mathrm{N}$ to $52.07^{\circ} \mathrm{N}$ latitude. Weather data were collected from the nearest available

\section{R. K. Bush $(\square)$}

University of Wisconsin-Madison,

2500 Overlook Terrace,

Madison, WI 53705, USA

e-mail: rkb@medicine.wisc.edu weather-reporting station. A regression analysis was performed to ascertain the relationship between the duration of ragweed pollination and the frost-free interval.

Results: The data indicated that the length of the ragweed pollen season at latitudes above $44^{\circ} \mathrm{N}$ have increased by as much as 13 to 27 days in these locales in the United States and Canada.

Discussion: This study has important implications for patients suffering from allergic rhinoconjunctivitis and asthma caused by ragweed sensitivity and for the physicians caring for them. The data indicated that the area's most impacted by global warming trends are experiencing a prolongation of the ragweed pollen season, and that similar effects are likely to occur with other pollen seasons (eg, earlier onset of tree pollen seasons). The increase in duration of the ragweed pollen season will translate into increased health care expenditures and could lengthen the suffering of patients with seasonal allergic diseases.

\section{Comments}

Whether the increasing duration of pollen seasons will lead to an increase in the prevalence of allergic disease has yet to be determined. Nonetheless, this study has important implications for public health and emphasizes the need for further scientific investigations and solutions to warming at higher latitudes.

\section{Disclosure}

Dr. Bush has received money through an IRA held in conjunction with Teva Pharmaceutical Industries. 